\title{
Purification of high purity docosahexaenoic acid from Schizochytrium sp. SH103 using preparative-scale HPLC
}

\author{
Chi-Eun Oh', Gap-Jin Kim², Seung-Jin Park', Seunghoon Choi' ${ }^{1}$ Min-Joo Park', O-Mi Lee ${ }^{3}$ Jeong-Woo Seo ${ }^{4}$ \\ and Hong-Joo Son ${ }^{1,5^{*}}$ (D)
}

\begin{abstract}
High purity polyunsaturated fatty acids (>95\%) are essential for the synthesis of specialized pro-resolving lipid mediators (SPMs), such as protectins, resolvins, and maresins, which are used for clinical application. To date, high purity (>95\%) eicosapentaenoic acid (EPA; C20:5n3) and docosahexaenoic acid (DHA; C22:6n3) have been produced through various manufacturing steps using fish oil. In this study, we optimized preparative high performance liquid chromatography (HPLC) process to purify high-purity DHA ethyl ester (DHAee; >98\%) from oleaginous microalgae Shizochytrium sp. SH103 containing at least 34\% DHA content. The purity and yield of DHA were determined by reverse phase chromatography with changing the mobile phase velocity, loading amount, and mobile phase composition. On a semi-preparative scale, optimal DHA separation in isocratic elution was obtained with a mobile phase velocity of $0.5 \mathrm{~mL} / \mathrm{min}$, a loading amount of $10 \mathrm{mg} / \mathrm{mL}$, and mobile phase composition of methanol/water (96:4, $\mathrm{v} / \mathrm{V}$ ), wherein the purity of DHA was $98.5 \%$. This separation was scaled up to a preparative column, resulting in $99.0 \%$ DHA fraction with a yield of $79.8 \%$. This result suggests that a large amount of high purity DHA can be produced from microalgae when scaling up a preparative column to an industrial column.
\end{abstract}

Keywords: High purity DHA, Preparative HPLC, Purification, Shizochytrium sp.

\section{Introduction}

The intake of polyunsaturated omega-3 fatty acids, including eicosapentaenoic acid (EPA; C20:5 $\omega-3)$ and docosahexaenoic acid (DHA; C22:6 $\omega-3)$, has been shown to benefit for human health through a variety of clinical studies. It makes several highly beneficial effects on the prevention against hypertriglyceridemia, atherosclerosis, and cardiovascular health $[1,2]$. Several reports have suggested that these compounds are also effective against a variety of other diseases such as asthma, Crohn's disease, Parkinson's disease, Alzheimer's disease, rheumatoid arthritis, skin diseases, and metabolic syndrome [3, 4]. In

\footnotetext{
*Correspondence: shjoo@pusan.ac.kr

1 Department of Life Science and Environmental Biochemistry, Pusan

National University, Miryang 50463, Republic of Korea

Full list of author information is available at the end of the article
}

particular, DHA is an essential constituent in the brain and eye development during infancy and has been shown to help improve the learning ability of preschool children through clinical trials $[5,6]$.

Recently, many studies have been carried out to produce omega- 3 fatty acids on an industrial scale as sources of fatty acids replacing fish. Microalgae are the primary producer of marine ecosystems that accumulate polyunsaturated fatty acids (PUFAs) containing EPA and DHA in cells $[7,8]$. In particular, Schizochytrium is a potential omega-3 fatty acid producer whose lipid content in dried biomass is higher than $30 \%$. Fish oil usually contains $10 \%$ to $20 \%$ DHA, while Schizochytrium lipid contains more than 25\% DHA [9-11]. Unlike fish-derived oils, Schizochytrium lipid contains less PUFAs similar to DHA, which is useful for separating DHA with high purity [12]. 
Most of the unrefined oils extracted from fish and microalgae contain fatty acids EPA and DHA attached to glycerol. In general, the method of increasing the omega-3 fatty acids content in triglyceride-type lipids extracted from fish and microalgae is very limited, so lipids must be converted to fatty acid ethyl ester (FAEE) form. Since esterified oil contains other impurities as well as target fatty acids, and methods have been proposed to increase the purity of the specific fatty acids by removing impurities. These methods include molecular distillation, low-temperature crystallization, urea adduct formation, simulated moving bed chromatography (SMB) and supercritical fluid chromatography [13]. However, other methods except for chromatography, could not produce omega- 3 fatty acids with a purity of $90 \%$ or more $[14,15]$. Although the urea adduct formation is a cost-effective method, it can produce carcinogenic alkyl carbamates [16]. In addition, molecular distillation requires high temperature under vacuum to remove undesirable impurities, which creates the risk of oxidation, polymerization and production of trans-isomers of omega-3 fatty acids [17]. This indicates that chromatographic method is suitable for obtaining pharmaceutical levels of high purity omega-3 fatty acids. In particular, preparative high performance liquid chromatography (HPLC) has been extensively studied to separate and purify EPA or DHA. Dillon et al. [18] reported that 95\% EPA and 99\% DHA were obtained from fish oil ethyl ester using HPLC equipped with a column filled with silver thiolate material. Giménez et al. [19] obtained $94.3 \%$ of EPA and $81.4 \%$ of arachidonic acid by reversed phase chromatography using a column with octadecyl bonded silica stationary phase.

Although many drugs using high-purity EPA are currently being developed, DHA is also a potential candidate for the treatment of various diseases. In addition to DHA, specialized pro-resolved lipid mediators (SPMs) derived from DHA are also promising candidates, which are potent bioactive lipids that relieve inflammation and modulate transient receptor translocation channels [20]. Through a series of bioconversion processes, DHA is converted to mediators such as D-series resolvins (RvD1-RvD6) and protectin D1 [21]. A recent study has shown that D-series mediators, including the intermediate hydroxy DHA (17S/R-HDHA), inhibit the production of inflammatory cytokines and are effective against a variety of diseases including lung injury, peritonitis, and atherosclerosis [22]. Protectin D1, a dihydroxy DHA, has also been shown to reduce oxidative stress-induced apoptosis in retinal pigment epithelial cells, and enhance phagocytosis of macrophages [23].

In this study, we established a process to produce API-grade high purity DHA (>97.5\%) from DHA-rich
Schizochytrium sp. SH103 using preparative HPLC equipped with a large-scale column. For this purpose, DHA separation conditions such as mobile phase velocity, sample loading amount, and mobile phase composition were first investigated on a small-scale column, and the purity and impurities of DHA were determined by gas chromatography (GC). Furthermore, repeated production of high purity DHA was carried out using largescale HPLC to confirm the reproducibility of established separation conditions.

\section{Materials and methods \\ Reagents and chemicals}

All solvents used in this study were analytical reagent grade for GC or HPLC. FAEEs and methyl tricosanoate for GC analysis were purchased from $\mathrm{Nu}$-Check Prep. Inc., USA. Butylhydroxytolune and trimethylpentane were purchased from Sigma-Aldrich (St. Louis, MO, USA).

\section{Microorganism and sample preparation Microalgae and culture conditions}

The microalgae used in this study was Schizochytrium sp. SH103 (KCTC 21861BP) donated by Microbiological research center, Korea research institute of bioscience and biotechnology (KRIBB) [24]. Seed culture was performed as follows; the cells were grown in a basal medium $(60 \mathrm{~g} / \mathrm{L}$ glucose, $10 \mathrm{~g} / \mathrm{L}$ yeast extract, $9 \mathrm{~g} / \mathrm{L}$ $\mathrm{KH}_{2} \mathrm{PO}_{4}, 10 \mathrm{~g} / \mathrm{L}$ sea salt, $2 \mathrm{mg} / \mathrm{L}$ tetracycline, vitamin mixture [thiamin $9.5 \mathrm{mg} / \mathrm{L}$, biotin $0.2 \mathrm{mg} / \mathrm{L}$ and cyanocobalamin $1.0 \mathrm{mg} / \mathrm{L}]$ ) for 2 days at $28{ }^{\circ} \mathrm{C}$ and $125 \mathrm{rpm}$ on a rotary shaker. Batch fermentation for the production of lipids containing DHA was performed using a $5 \mathrm{~L}$ jar fermenter. Five hundred milliliter of the seed culture was inoculated into the jar fermenter containing $3 \mathrm{~L}$ of the basal medium. The cultivation was carried out for $60 \mathrm{~h}$ at $28{ }^{\circ} \mathrm{C}$ with $200 \mathrm{rpm}$ and $3.5 \mathrm{v} / \mathrm{v} / \mathrm{min}$. pH was initially adjusted to 6.0 by adding ammonia solution and $0.5 \mathrm{~mL}$ of antifoam agent per hour was added to prevent the foam formation.

\section{Lipid extraction and transesterification}

The fermentation broth was centrifuged at $6000 \mathrm{~g}$ for $15 \mathrm{~min}$ at $4{ }^{\circ} \mathrm{C}$ to remove the culture supernatant. The recovered cells were washed twice with distilled water and dried for $24 \mathrm{~h}$ using a vacuum freeze dryer. The resulting dried cells were extracted with a 20 -fold volume of chloroform:methanol $(2: 1, \mathrm{v} / \mathrm{v})$ for $20 \mathrm{~min}$. The extract was filtered through Whatman No. 1 filter paper to remove cell debris and then separated into two liquid layers by centrifugation $(1000 g)$. The lower chloroform layer containing lipids was pooled and concentrated using a rotary evaporator. 
The acid-catalyzed transesterification was carried out to convert the extracted lipids to fatty acid ethyl esters (FAEEs). The reaction mixture contained lipid, ethanol and sulfuric acid at a ratio of 1:10:0.4 $(\mathrm{w} / \mathrm{w})$, and the reaction was performed at $70{ }^{\circ} \mathrm{C}$ for $2 \mathrm{~h}$. After completion of the reaction, the reactants were transferred into a separating funnel and separated into two phases by adding water. The lower layer was discarded and $500 \mathrm{~mL}$ of hot water was added to the upper layer (FAEEs layer) [25]. This process was repeated until only a clean upper layer was obtained, and the final solution was dried in a vacuum.

\section{Semi-preparative HPLC system}

The small-scale separations were carried out with an Agilent 1100 HPLC system (Agilent, USA) equipped with binary pumps and UV detector. Considering the fact that the fatty acid converted to the ethyl ester form was nonpolar, it was separated using a reverse phase chromatography column $\left(C_{18}\right.$ column; $250 \mathrm{~mm} \times 4.6 \mathrm{~mm} \times 20 \mu \mathrm{m}$; Young Jin Biochrom Co., Korea). To optimize separation conditions on a semi-preparative scale, two small columns were connected by a connector with a dead volume of $20 \mu \mathrm{L}$, then the mobile phase velocity, sample loading amount, and mobile phase composition were varied as shown in Figs. 1, 2, 3 and 4. The purity of DHA in each fraction was confirmed by gas chromatography-flame ionization detector (GC-FID) and expressed as an area \%.

\section{Preparative HPLC system}

The preparative-scale separations were conducted on a preparative HPLC system (Prominence module system, Shimadzu Corporation, Japan) consisting of manual injector, UV-VIS detector, binary pumps, and fraction

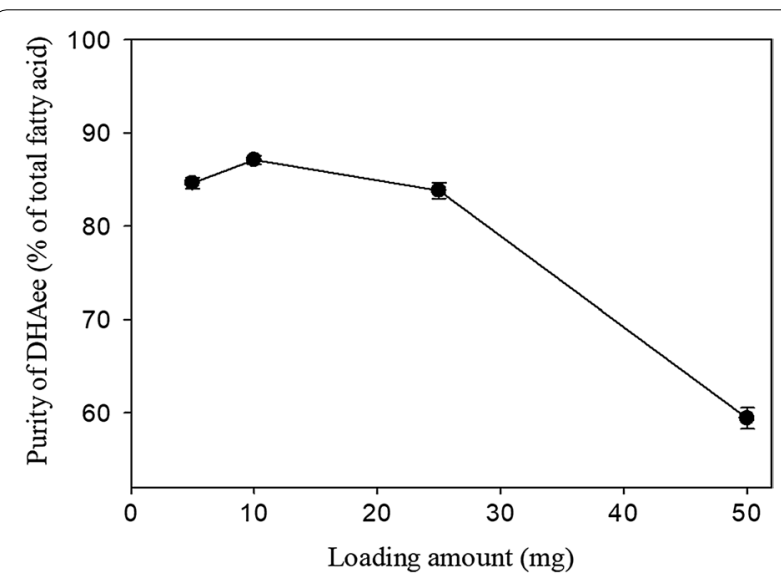

Fig. 1 The relationship between loading amount and DHA purity. Methanol was used as the mobile phase at $1 \mathrm{~mL} / \mathrm{min}$. Error bars ( \pm SDs) are shown when larger than the symbol collector. Chromatographic analysis was carried out using a large-scale $\mathrm{C}_{18}$ column $(500 \mathrm{~mm} \times 50 \mathrm{~mm} \times 20 \mu \mathrm{m})$. The column temperature was maintained at $40{ }^{\circ} \mathrm{C}$; detection was carried out at $210 \mathrm{~nm}$. Sample was directly injected into the injector using a $10 \mathrm{~mL}$ sample loop. Lab solutions software version 5.58 was used for HPLC control and data acquisition.

\section{Analytical methods Analysis of FAEEs composition}

The FAEEs were determined by using GC-FID (6890N, Agilent, USA) equipped with a capillary column HP-5 $(30 \mathrm{~m} \times 0.32 \mathrm{~mm} \times 0.25 \mathrm{~mm}$; Agilent, USA). The initial column temperature was $150{ }^{\circ} \mathrm{C}$ for $2 \mathrm{~min}$. The temperature was then increased to $270{ }^{\circ} \mathrm{C}$ at a rate of $10{ }^{\circ} \mathrm{C} / \mathrm{min}$ and held for $1 \mathrm{~min}$. The injector and detector temperatures were $250{ }^{\circ} \mathrm{C}$ and $300{ }^{\circ} \mathrm{C}$, respectively. $\mathrm{N}_{2}$ was used as carrier gas at a split ratio of 50:1. Injection volume was $1 \mu \mathrm{L}$. FAEEs were identified by comparison of retention times with standards and quantified by directly taking area $\%$ as weight $\%$.

\section{Quantitative determination of DHAee content}

To determine the content of DHA in the lipid extracted from Schizochytrium sp. SH103, the analysis was carried out by the method of European Pharmacopoeia 5.0 01/2005: 20,429 using GC-FID (7890N, Agilent, USA) with a capillary column CPWAX $(30 \mathrm{~m} \times 0.32 \mathrm{~mm} \times 0.25 \mathrm{~mm}$; Agilent, USA). The column temperature was maintained at $170{ }^{\circ} \mathrm{C}$ for $2 \mathrm{~min}$, increased to $240{ }^{\circ} \mathrm{C}\left(5^{\circ} \mathrm{C} / \mathrm{min}\right)$ and held for $2.3 \mathrm{~min}$. The injector was maintained at $250{ }^{\circ} \mathrm{C}$ and detector at $270{ }^{\circ} \mathrm{C}$. The carrier gas was helium at $0.6 \mathrm{~mL} / \mathrm{min}$. The sample injection volume was $1 \mu \mathrm{L}$, and the injector was operated at a split ratio of 200:1.

Methyl tricosanoate and DHAee were used as internal and external standards, respectively. A reference solution was prepared as follows: $60 \mathrm{mg}$ of DHAee and $70 \mathrm{mg}$ of methyl tricosanoate were accurately weighed into a $10 \mathrm{~mL}$ volumetric flask. The standards were dissolved with a $50 \mathrm{mg} / \mathrm{L}$ solution of butylhydroxytoluene in trimethylpentane and diluted to an appropriate volume. The test solution was the same as the reference solution preparation except for the addition of $250 \mathrm{mg}$ of samples instead of DHAee. To calculate the concentration $(\mathrm{mg} / \mathrm{g})$ of DHAee in total lipids, the following equation was used [26]:

$$
\text { DHAee }(\mathrm{mg} / \mathrm{g})=A x \times \frac{A 3}{m 3} \times \frac{m 1}{A 1} \times \frac{m x, r}{A x, r} \times \frac{1}{m 2} \times 1000
$$

where $\mathrm{m} 1$ and $\mathrm{m} 2$ are the weight $(\mathrm{mg})$ of the internal standard and the sample in the test solution, respectively, $\mathrm{m} 3$ is the weight $(\mathrm{mg})$ of the internal standard 
Table 1 Fatty acid composition of Schizochytrium sp. SH103 oil

\begin{tabular}{lcc}
\hline Fatty acid & \multicolumn{1}{c}{$\begin{array}{l}\text { Content (\% } \\
\text { of total fatty } \\
\text { acid) }\end{array}$} \\
\hline Myristic acid & $\mathrm{C} 14: 0$ & $2.36 \pm 0.01$ \\
Pentadecanoic acid & $\mathrm{C} 15: 0$ & $0.17 \pm 0.00$ \\
Palmitic acid & $\mathrm{C} 16: 0$ & $49.84 \pm 0.03$ \\
Palmitoleic acid & $\mathrm{C} 16: 1 \mathrm{n} 7$ & $0.22 \pm 0.02$ \\
Linoleic acid & $\mathrm{C} 18: 2 \mathrm{n} 6$ & $1.28 \pm 0.01$ \\
Eicosenoic acid & $\mathrm{C} 20: 1 \mathrm{n} 9$ & $0.33 \pm 0.00$ \\
Arachidonic acid & $\mathrm{C} 20: 4 \mathrm{n} 6$ & $0.26 \pm 0.00$ \\
Eicosapentaenoic acid & $\mathrm{C} 20: 5 \mathrm{n} 3$ & $0.42 \pm 0.02$ \\
Docosapentaenoic acid & $\mathrm{C} 22: 5 \mathrm{n} 3$ & $0.86 \pm 0.02$ \\
Docosapentaenoic acid & $\mathrm{C} 22: 5 \mathrm{n} 6$ & $9.12 \pm 0.04$ \\
Docosahexaenoic acid & $\mathrm{C} 22: 6 \mathrm{n} 3$ & $34.96 \pm 0.03$ \\
\hline
\end{tabular}

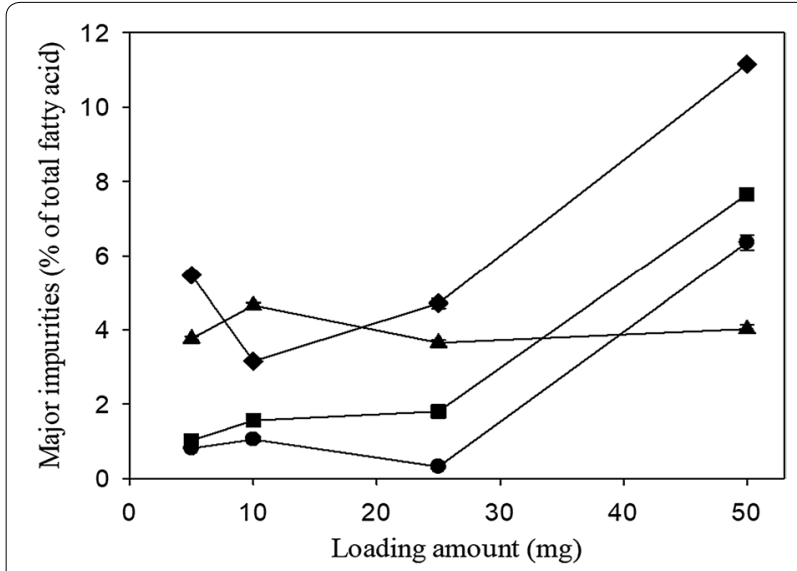

Fig. 2 Changes in purity of major impurities depending on the loading amount. Methanol was used as the mobile phase at $1 \mathrm{~mL} /$ min. Filled circle — C14:0; filled square — C16:0; filled diamondC16:1n7; filled triangle - C22:5n6. Error bars ( \pm SDs) are shown when larger than the symbol

in the reference solution, $\mathrm{mx}, \mathrm{r}$ is the weight $(\mathrm{mg})$ of DHAee in the reference solution. Ax and Ax, $r$ are the peak areas corresponding to DHAee in the chromatogram obtained with the test solution and the reference solution, respectively, and $\mathrm{A} 1$ and $\mathrm{A} 3$ are the peak areas corresponding to the internal standard in the chromatogram obtained with the test solution and the reference solution, respectively.

All experiments and analyzes were performed at least in triplicate unless otherwise specified. Experimental results were presented as mean \pm standard deviation.

\section{Result and discussion}

Lipid and FAEE composition of Schizochytrium sp. SH 103

Schizochytrium sp. SH103 cultivated in the basal medium using a fermenter showed a dry cell weight of $25 \mathrm{~g} / \mathrm{L}$ and a lipid content of $11.6 \mathrm{~g} / \mathrm{L}$ after $60 \mathrm{~h}$ of incubation. GC analysis indicated that the lipid was completely converted to FAEE by acid-catalyzed transesterification, and the DHA content was $313 \mathrm{mg} / \mathrm{g}$. As shown in Table 1, the major fatty acids of Schizochytrium sp. SH 103 were DHA 34.96\%, docosapentaenoic acid (DPA, C22:5n6) 9.12\% and palmitic acid (C16:0) 49.84\%. These values were slightly different from the results of Ju et al. [24] in DPA and DHA contents, which was thought to be due to differences in the culture method and the culture time.

\section{Optimization of separation conditions using semi-preparative HPLC system Influence of loading amount}

The ultimate goal of preparative chromatography is to produce the maximum amount of the target substance per sample injection. Therefore, we tried to determine the maximum loading amount of FAEEs derived from Schizochytrium sp. SH 103.

After each FAEEs sample of $5-50 \mathrm{mg} / \mathrm{mL}$ (in methanol) was injected into a semi-preparative scale $C_{18}$ column and fractionated at $1 \mathrm{~min}$ intervals, the purity of DHA in each fraction was confirmed by GC-FID. Figure 1 shows the area \% of the fraction showing the highest purity according to the loading amount; when the loading amount was $10 \mathrm{mg}$, the purity of DHA was the highest at $87.4 \%$. Although the difference in DHA purity was not significant in the range of 5 to $25 \mathrm{mg}$ of loading amount, it was found that the purity decreased sharply to $60.20 \%$ when $50 \mathrm{mg}$ was injected into the column. The major impurities in all experimental groups were found to be DPA, myristic acid (C14:0), palmitoleic acid (C16:1n7), and palmitic acid; at $10 \mathrm{mg}$ injection, DPA, myristic acid, palmitoleic acid, and palmitic acid were $4.59 \%, 0.65 \%$, $3.30 \%$, and $1.62 \%$, respectively. However, when $50 \mathrm{mg}$ was injected, the concentration of impurities except DPA increased (Fig. 2). On the other hand, when $50 \mathrm{mg}$ was injected, the retention time of FAEEs having $\mathrm{C} 14$ to $\mathrm{C} 22$ carbon was similar to that of DHA, which was presumed to be due to a decrease in the separation ability by excessive loading amount (injection overload).

\section{Influence of mobile phase velocity}

The effect of mobile phase velocity on DHA purity and retention time was investigated, and the result is shown in Additional file 1: Fig. S1. The highest DHA purity was $87.4 \%$ at $1.00 \mathrm{~mL} / \mathrm{min}, 89.4 \%$ at $0.50 \mathrm{~mL} / \mathrm{min}$ and $90.73 \%$ at $0.25 \mathrm{~mL} / \mathrm{min}$, respectively. It was also found 
that the retention time of the main peak containing DHA increased from 14.81 to $59.27 \mathrm{~min}$ as the mobile phase velocity decreased. Although there was no significant change in the purity of the DHA depending on the mobile phase velocity, slower mobile phase velocity will lead to longer production time and lower productivity.

\section{Influence of mobile phase composition}

To investigate the effect of mobile phase composition on DHA separation, the amount of water in methanol was increased from 0 to $10 \%(\mathrm{v} / \mathrm{v})$ using a binary pump, and experiments were performed at a mobile phase velocity of $0.5 \mathrm{~mL} / \mathrm{min}$. As shown in Fig. 3 and Additional file 1: Fig. S2, the retention time was rapidly delayed from 29.33 to $117.63 \mathrm{~min}$ as the ratio of water to methanol increased. In addition, the height and sharpness of the main peak were reduced and the width was widened. The DHA purity increased from 89.34 to $98.51 \%$ with an increase in water ratio from 0 to $4 \%(\mathrm{v} / \mathrm{v})$; further increases with water up to $10 \%(\mathrm{v} / \mathrm{v})$ did not significantly affect the DHA purity. The column pressure also increased from 1.0 to 5.4 MPa depending on the ratio of water added.

The polarity difference of the mobile phase according to the solvent composition was an important factor in material separation. That is, increasing the polarity of the mobile phase has been found to improve the separation efficiency by delaying the retention time of the non-polar FAEE in the column. However, it has been reported that when fatty acids are separated using HPLC, the increased polarity of the mobile phase reduces column life and pump durability due to increased column pressure [18]. This study also showed that the major impurities, DPA and palmitic acid, were completely removed in fractions 15-17 when the water to methanol ratio was $4 \%(\mathrm{v} / \mathrm{v})$ (Additional file 1: Fig. S3 and Table S1). Therefore, it was thought that it would be advantageous to add water of $4 \%(\mathrm{v} / \mathrm{v})$ in methanol to obtain DHA with a target purity of $98 \%$ or more.

\section{Scale-up using preparative HPLC system}

Scale-up using preparative HPLC was designed to achieve a purity of more than $98 \%$ DHA from Schizochytrium sp. SH103 oil based on the separation conditions established using semi-preparative HPLC. Equivalent theoretical numbers and retention times in columns of various scales achieve the same purification performance. Therefore, in order to apply the separation conditions established using a semi-preparative column to the preparative column, the height of the column must be the same and the diameter must be increased [27]. Since the diameter of the column is a major factor affecting the loading amount per unit area of the column, the loading amount and mobile phase velocity according to the scale-up were calculated using the following equation [28].

$$
\begin{aligned}
& M_{p}=M_{s}\left(D_{p} / D_{s}\right)^{2} \\
& F_{p}=F_{s}\left(D_{p} / D_{s}\right)^{2}
\end{aligned}
$$
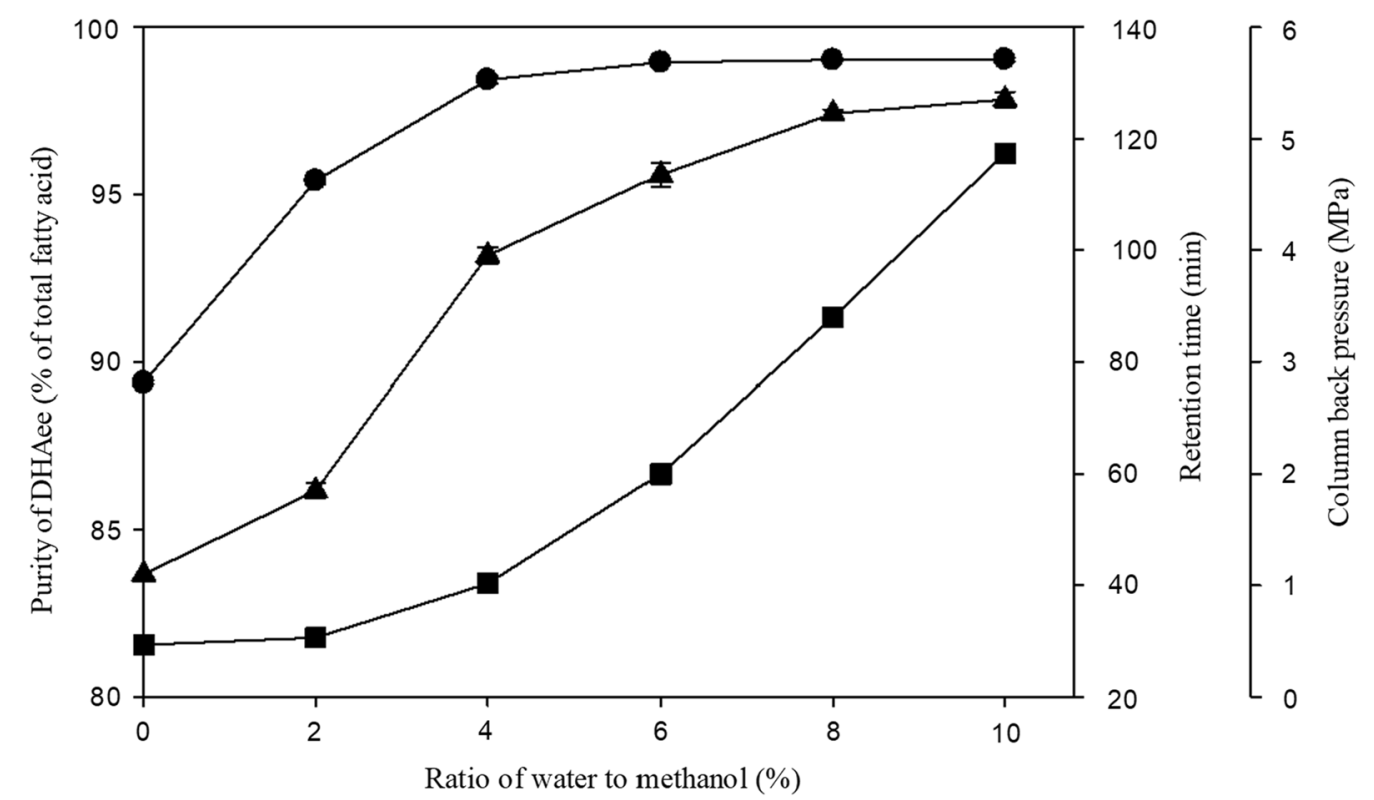

Fig. 3 Effect of mobile phase composition on DHA purity, column backpressure and retention time using water (0-10\%, v/v) in methanol at various concentrations. The mobile phase velocity $(0.5 \mathrm{~mL} / \mathrm{min})$ was held constant across all trials. Filled circle-DHA; filled square-retention time; filled triangle — column back pressure. Error bars ( \pm SDs) are shown when larger than the symbol 
where $M, F$, and $\mathrm{D}$ are loading amount, mobile phase velocity, and column diameter, respectively. Subscripts $s$ and $p$ are semi-preparative scale and preparative scale, respectively. $M_{s}$ and $F_{s}$ represent the optimal loading amount $(10 \mathrm{mg})$ and mobile phase velocity $(0.5 \mathrm{~mL} / \mathrm{min})$ for the semi-preparative scale established in the previous section, respectively. The loading amount and mobile phase velocity calculated by these equations for the scaleup conditions were $1200 \mathrm{mg}$ and $60.0 \mathrm{~mL} / \mathrm{min}$, respectively. Thus, $1200 \mathrm{mg}$ of FAEEs from Schizochytrium sp. SH103 oil was injected into a preparative HPLC system and aliquoted at $40 \mathrm{~mL} /$ fraction using an automatic fractionation program. The purity of DHA and impurities in each fraction were then checked to determine the optimum production zone.

As shown in Fig. 4, the average purity of DHA (peak 1) present in fractions $2-5$ was $99.5 \%$. In addition,
$0.25 \%$ eicosenoic acid (C20:1n9), $0.1 \%$ palmitoleic acid, 0.08\% palmitic acid, $0.03 \%$ pentadecanoic acid (C15:0) and $0.03 \%$ myristic acid were detected as impurities (Table 2). Meanwhile, the average purity of DPA (peak 2) present in fractions $10-13$ was $92.8 \%$. In this study, the target purity of DHA at the preparative scale level was $98 \%$ or more, so the optimal range for the production of high purity DHA was determined in fractions 2 to 5 .

The purity of DHA obtained through three repeated experiments was $98.87 \%, 98.88 \%$, and $99.10 \%$, respectively, with an average of $98.95 \%$ (Table 3). The recovery rate of DHA is another important factor, and the recovery rate calculated using the following equation was very high at $79.75 \%$. This suggests that the separation process performed in this study is reproducible and successful.

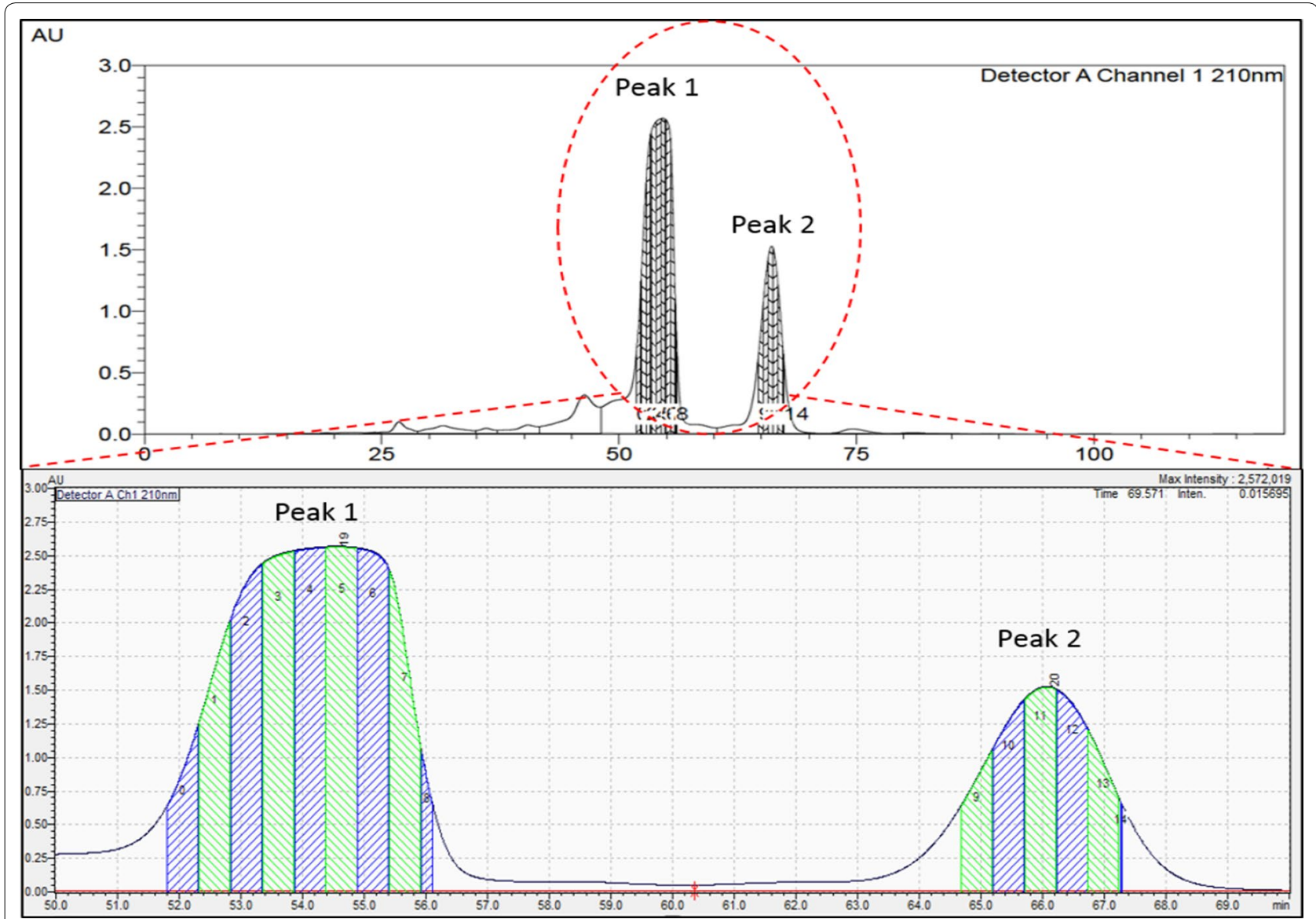

Fig. 4 Chromatogram of preparative HPLC fractional sections of FAEEs derived from Schizochytrium sp. SH103. Mobile phase (methanol-water 96:4, v/v); mobile phase velocity ( $60 \mathrm{~mL} / \mathrm{min})$; fractional amount (40 mL/vial); loading amount (1200 mg). Peak 1 and 2 represent DHA and DPA, respectively 
Table 2 Composition and content of fatty acid in the FAEEs fractions enriched using preparative HPLC

\begin{tabular}{|c|c|c|c|c|c|c|c|c|c|}
\hline \multirow[t]{2}{*}{ Fraction no } & \multicolumn{9}{|c|}{ Purity (\% of total fatty acid) } \\
\hline & $\mathrm{C} 22: 6 \mathrm{n} 3$ & $C 22: 5 n 6$ & $C 22: 5 n 3$ & C20:1n9 & C18:1 & C16:0 & C16:1n7 & C15:0 & C14:0 \\
\hline F0 & 91.35 & 0.00 & 0.00 & 0.00 & 0.00 & 0.00 & 0.00 & 0.00 & 8.65 \\
\hline F1 & 90.66 & 0.00 & 0.00 & 0.00 & 0.00 & 0.00 & 0.00 & 0.00 & 9.34 \\
\hline F2 & 99.47 & 0.00 & 0.00 & 0.09 & 0.00 & 0.11 & 0.19 & 0.00 & 0.14 \\
\hline F3 & 99.70 & 0.00 & 0.00 & 0.10 & 0.00 & 0.10 & 0.11 & 0.00 & 0.00 \\
\hline $\mathrm{F} 4$ & 99.72 & 0.00 & 0.00 & 0.19 & 0.00 & 0.09 & 0.00 & 0.00 & 0.00 \\
\hline F5 & 98.94 & 0.00 & 0.00 & 0.58 & 0.00 & 0.11 & 0.00 & 0.12 & 0.00 \\
\hline F6 & 95.84 & 0.00 & 0.00 & 2.81 & 0.00 & 0.00 & 0.00 & 0.00 & 0.00 \\
\hline F7 & 89.41 & 0.00 & 0.00 & 10.59 & 0.00 & 0.00 & 0.00 & 0.00 & 0.00 \\
\hline F8 & 0.00 & 0.00 & 0.00 & 0.00 & 0.00 & 0.00 & 0.00 & 0.00 & 0.00 \\
\hline F9 & 0.00 & 55.92 & 0.00 & 0.00 & 0.00 & 44.08 & 0.00 & 0.00 & 0.00 \\
\hline F10 & 0.00 & 92.80 & 3.10 & 0.00 & 0.00 & 3.95 & 0.16 & 0.00 & 0.00 \\
\hline F11 & 0.00 & 93.53 & 1.98 & 0.00 & 0.00 & 3.99 & 0.18 & 0.12 & 0.00 \\
\hline F12 & 0.00 & 93.69 & 1.39 & 0.00 & 0.00 & 4.24 & 0.21 & 0.11 & 0.00 \\
\hline F13 & 0.00 & 91.22 & 1.11 & 0.86 & 0.14 & 5.22 & 0.38 & 0.19 & 0.12 \\
\hline F14 & 0.00 & 62.71 & 0.00 & 0.00 & 0.00 & 37.29 & 0.00 & 0.00 & 0.00 \\
\hline
\end{tabular}

Table 3 Result of repeatability according to production batches of high purity DHA using preparative HPLC

\begin{tabular}{llll}
\hline Batch number & DHA purity (\%) & $\begin{array}{l}\text { DHA content } \\
\text { (mg/g) }\end{array}$ & $\begin{array}{l}\text { Recovery rate } \\
\text { (\%) }\end{array}$ \\
\hline 1 batch & 98.87 & 974 & 79.72 \\
2 batch & 98.88 & 974 & 80.00 \\
3 batch & 99.10 & 975 & 79.52 \\
Average & $98.95 \pm 0.13$ & $974 \pm 0.50$ & $79.75 \pm 0.20$ \\
\hline
\end{tabular}

$$
\begin{aligned}
& \text { Recovery rate of DHA ethyl ester }(\%) \\
& =[(W p \times A p) /(W i \times A i)] \times 100
\end{aligned}
$$

where $W_{i}$ and $W_{p}$ are the loading amount (g) and product amount (g), respectively, and $A_{i}$ and $A_{p}$ are the DHAee content $(\mathrm{mg} / \mathrm{g})$ in the injected sample and product, respectively.

In conclusion, DHA from Shizochtriumsp. SH103 oil was highly purified using preparative HPLC in a onestep process. The optimized conditions for purifying DHA were methanol/water $(96: 4, \mathrm{v} / \mathrm{v})$ as the mobile phase, mobile phase velocity of $60 \mathrm{~mL} / \mathrm{min}$, and loading amount of $1200 \mathrm{mg}$. The DHA purity separated under these conditions was $98.95 \%$ and the recovery rate was $79.75 \%$. Omega-3 FAEEs is being separated and purified by conventional complex manufacturing processes such as vacuum distillation and urea adduct formation. Nevertheless, high-purity DHA (>98\%) production using preparative HPLC can be a very attractive method in terms of industrial-scale and economics. Furthermore, the purification method established in this study is expected to greatly accelerate the application of DHA as medical research material and drug.

\section{Supplementary information}

Supplementary information accompanies this paper at https://doi. org/10.1186/s13765-020-00542-w.

Additional file 1: Table S1. Composition and content of fatty acid in the FAEEs fractions enriched using semi-preparative HPLC. Fig. S1. Effect of mobile phase velocity on DHA purity and retention time. Methanol was used as the mobile phase. DHA ethyl ester; retention time. Error bars ( \pm SDs) are shown when larger than the symbol. Fig. S2. Changes of chromatograms according to mobile phase composition using water $(0-10 \%, v / v)$ in methanol at various concentrations. The mobile phase velocity $(0.5 \mathrm{~mL} / \mathrm{min})$ was held constant across all trials. Fig. S3. Chromatogram of semi-preparative HPLC fractional sections of FAEEs derived from Schizochytrium sp. SH 103. Mobile phase (methanol-water 96:4, v/v); mobile phase velocity $(0.5 \mathrm{~mL} / \mathrm{min})$; fractional interval (1 min/vial); loading amount (10 mg).

Acknowledgements

Not applicable.

Authors' contributions

C-EO, S-JP, SC and M-JP performed the experiments. J-WS participated in analyzing and interpreting the results. G-JK, O-ML and H-JS designed the experiments and wrote the paper. All authors read and approved the final manuscript.

Funding

Not applicable.

Availability of data and materials Not applicable. 


\section{Competing interests \\ Not applicable.}

\section{Author details}

${ }^{1}$ Department of Life Science and Environmental Biochemistry, Pusan National University, Miryang 50463, Republic of Korea. ${ }^{2}$ PharmaMega Inc., Busan 48055, Republic of Korea. ${ }^{3}$ Plant Quarantine Technology Center, Animal and Plant Quarantine Agency, Gimcheon 39660, Republic of Korea. ${ }^{4}$ Microbial Biotechnology Research Center, Jeonbuk Branch Institute, Korea Research Institute of Bioscience and Biotechnology (KRIBB), Jeongeup 56212, Republic of Korea. ${ }^{5}$ Life and Industry Convergence Research Institute, Pusan National University, Miryang 50463, Republic of Korea.

Received: 29 July 2020 Accepted: 9 September 2020

Published online: 16 September 2020

\section{References}

1. Harris WS, Connor WE, Inkeles SB, Illingworth DR (1984) Dietary omega-3 fatty acids prevent carbohydrate-induced hypertriglyceridemia. Metab Clin Exp 33:1016-1019

2. Connor WE (2000) Importance of $n-3$ fatty acids in health and disease. Am J Clin Nutr 71:171S-175S

3. Lorente-Cebrián S, Costa AG, Navas-Carretero S, Zabala M, Martínez JA, Moreno-Aliaga MJ (2013) Role of omega-3 fatty acids in obesity, metabolic syndrome, and cardiovascular diseases: a review of the evidence. J Physiol Biochem 69:633-651

4. Janssen Cl, Kiliaan AJ (2014) Long-chain polyunsaturated fatty acids (LCPUFA) from genesis to senescence: the influence of LCPUFA on neural development, aging, and neurodegeneration. Prog Lipid Res 53:1-17

5. Birch EE, Garfield S, Castañeda Y, Hughbanks-Wheaton D, Uauy R, Hoffman D (2007) Visual acuity and cognitive outcomes at 4 years of age in a double-blind, randomized trial of long-chain polyunsaturated fatty acid-supplemented infant formula. Early Hum Dev 83:279-284

6. Innis SM (2008) Dietary omega 3 fatty acids and the developing brain. Brain Res 1237:35-43

7. Hong W, Rairakhwada D, Seo P, Park S, Hur B, Kim CH, Seo J (2011) Production of lipids containing high levels of docosahexaenoic acid by a newly isolated microalga, Aurantiochytrium sp. KRS101. Appl Biochem Biotechnol 164:1468-1480

8. Gupta A, Barrow CJ, Puri M (2012) Omega-3 biotechnology: Thraustochytrids as a novel source of omega-3 oils. Biotechnol Adv 30:1733-1745

9. Ratledge C (2004) Fatty acid biosynthesis in microorganisms being used for single cell oil production. Biochimie 86:807-815

10. Raghukumar S (2008) Thraustochytrid marine protists: production of PUFAs and other emerging technologies. Mar Biotechnol 10:631-640

11. Strobel C, Jahreis G, Kuhnt K (2012) Survey of n-3 and n-6 Polyunsaturated fatty acids in fish and fish products. Lipids Health Dis 11:144-153

12. Yokochi T, Honda D, Higashihara T, Nakahara T (1998) Optimization of docosahexaenoic acid production by Schizochytrium limacinum SR21. Appl Microbiol Biotechnol 49:72-76

13. Dong Q, Li M, Yang Y, Bao Z, Yang Q, Zhang Z, Ren Q (2018) Separation of eicosapentaenoic acid ethyl ester and docosahexaenoic acid ethyl ester by simulated moving bed chromatography. Chin J Chromatogr 36:858-865
14. Li M, Bao Z, Xing H, Yang Q, Yang Y, Ren Q (2015) Simulated moving bed chromatography for the separation of ethyl esters of eicosapentaenoic acid and docosahexaenoic acid under nonlinear conditions. J Chromatogr A 1425:189-197

15. Kim GJ, Son HJ, Whang WS, Koo YM, Kim JI, Yang JH (2011) High-purity purification method for omega-3 highly unsaturated fatty acids. U.S Patent No. 20110091947A1.

16. Fagan P, Wijesundera C (2013) Rapid isolation of omega-3 long-chain polyunsaturated fatty acids using monolithic high performance liquid chromatography columns. J Sep Sci 36:1743-1752

17. Shahidi F, Wanasundara UN (1998) Omega-3 fatty acid concentrates: nutritional aspects and production technologies. Trends Food Sci Technol 9:230-240

18. Dillon JT, Aponte JC, Tarozo R, Huang Y (2013) Purification of omega-3 polyunsaturated fatty acids from fish oil using silver-thiolate chromatographic material and high performance liquid chromatography. J Chromatogr A 1312:18-25

19. Giménez GA, Ibáñez GM, Robles MA, Molina GE, García SS, Esteban CL (1998) Downstream processing and purification of eicosapentaenoic (20: $5 n-3)$ and arachidonic acids (20: $4 n-6)$ from the microalga Porphyridium cruentum. Bioseparation 7:89-99

20. Wall R, Ross RP, Fitzgerald GF, Stanton C (2010) Fatty acids from fish: the anti-inflammatory potential of long-chain omega-3 fatty acids. Nutr Rev 68:280-289

21. Valdes AM, Ravipati S, Menni C, Abhishek A, Metrustry S, Harris J, Nessa A, Williams FMK, Sector TD, Doherty M, Chapman V, Barrett DA (2017) Association of the resolving precursor 17-HDHA, but not D- or E-series resolvins, with heat pain sensitivity and osteoarthritis pain in humans. Sci Rep 7:10748-10756

22. López-Vicario C, Rius B, Alcaraz-Quiles J, García-Alonso V, Lopategi A, Titos E, Clària J (2015) Pro-resolving mediators produced from EPA and DHA: overview of the pathways involved and their mechanisms in metabolic syndrome and related liver diseases. Eur J Pharmacol 15:133-143

23. Weylandt KH, Chiu C, Gomolka B, Waechter SF, Wiedenmann B (2012) Omega-3 fatty acids and their lipid mediators: towards an understanding of resolvin and protectin formation. Prostag Oth Lipid Meditors 97:73-82

24. Ju HJ, Oh BR, Ko DJ, Heo SY, Lee JJ, Kim YM, Yang KS, Seo JW, Hong WK, Kim CH (2018) Boosting productivity of heterotrophic microalgae by efficient control of the oxygen transfer coefficient using a microbubble sparger. Algal Res 41:1-7

25. Bligh EG, Dyer WJA (1959) Rapid method of total lipid extraction and purification. Can J Biochem Physiol 37:911-917

26. Nurnadia AA, Azrina A, Amin I, Suryati MA, Muhammad RR (2013) Quantitative determination of fatty acids in marine fish and shellfish from warm water of Straits of Malacca for nutraceutical purposes. Biomed Res Int 2013:284329

27. Huber U, Majors R (2007) Principles in preparative HPLC. Agilent Technologies Inc., Waldbronn

28. Medina AR, Giménez AG, Camacho FG, Pérez JS, Grima EM, Gómez AC (1995) Concentration and purification of stearidonic, eicosapentaenoic, and docosahexaenoic acids from cod liver oil and the marine microalgal Isochrysis galbana. J Am Oil Chem Soc 72:575-583

\section{Publisher's Note}

Springer Nature remains neutral with regard to jurisdictional claims in published maps and institutional affiliations. 